\title{
The Specifics of Rural School in Russia: Historical and Pedagogical Analysis
}

\author{
Yevgeniya Yeretnova*, Elena Sartakova
}

\author{
Tomsk State Pedagogical University, Tomsk, Russia \\ Corresponding author. Email:4elsi_91@mail.ru
}

\begin{abstract}
The article proposes historical and pedagogical analysis of the leading provisions of the concept of the rural school development. The purpose of the study is to identify on the basis of historical and pedagogical analysis and to systematize the peculiarities of rural school as one of the leading factors of modernization of education of Russia.

The novelty of the study is to clarify the content of the rural school as a pedagogical system. The theoretical significance of the study is that scientific ideas about the rural school of Russia have been systematized on the basis of the carried out historical and pedagogical analysis and patterns of development of the modern rural school in Russia have been established (formation of the rural school as an open network general education organization; the focus of the content of the educational process on the design and implementation of variable educational services, which ensure the formation of social and personal success of graduates; feasibility of modeling rural schools taking into account national-regional specificities, etc.).
\end{abstract}

Keywords: information society, rural school, conceptual model, peculiarities of life organization

\section{INTRODUCTION}

In the last decades of the 20th century the most significant phenomenon in the world community was the formation of an information economy connected with the emergence of network forms of organization of social and economic activities based on the active use of informational communication technologies by the State, citizens and economic entities and the global electronic network of the Internet in production, distribution, exchange and consumption. The formation of the network economy has contributed to the innovative development of the social sphere and the formation of a modern education system [1]. In the course of numerous educational reforms of the beginning of the XXI century its abris was defined according to the demands of the emerging information society, criteria related to improving the quality, accessibility, efficiency of educational services.

However, nowadays the criterion of accessibility has not met the full scope of requests for various educational programs including such as inclusive, in-depth, developing, special, additional. In terms of quality the leading educational results so far are subject-matter. Efficiency is often determined by economic indicators and the practice of balancing the whole range of educational services is not common.

We share the view of a number of experts (A. G. Asmolov, O. G. Prikot, A. M. Tsirulnikov, etc.) that most educational projects were organizational and economic in nature, Their "linear" scenario often didn't include the national-regional peculiarities of the regions of the Russian Federation. However, such a phenomenon as a rural school has a significant impact on the process of modernization of the Russian education. Despite their significant reduction (from 48.6 thousand (1991) to 22.895 thousand (2017)), this group of general education organizations accounts for up to $70 \%$ of all schools in the Russian Federation [2].

In the process of establishing the modern system of education that meets the needs of the developing information society the rural educational institutions were faced with numerous tasks related to the implementation of specialized training, additional educational programs, out-of-school activities, programs for the development of children 's talents, education, inclusive education, resource provision, including personnel, etc. However, the capacity to meet these challenges in most rural schools has been limited in resources, which has often contributed to a weak level of implementation, and often simply a simulation of the solution [3].

It is possible that the formation of a modern model of education in Russia requires not only new approaches, appropriate management mechanisms, but the implementation of a new national program for the development of the rural schools.

At the same time there is a number of fair arguments: 
1) In the context of the "demographic boom" the number of students increases, accordingly the number of small schools decreases [4], which is not statistically confirmed. 2) The development of the agriculture contributes to the increase of the number of jobs, the emergence of a modern way of life of villagers, the reduction of migration flow, the consolidation of young people in rural areas.

3) The development of modern social infrastructure contributes to increasing the mobility of the population, erasing the boundaries between the city and the village.

4) Informatization, digitalization, network interaction (offline and online) as leading mechanisms of the rural school development, as well as creation of modern material and technical base equalize peculiarities of activity of this group of educational institutes.

They are limited socio-cultural relations, small number of the school collective, limited opportunities for additional education, proximity to the nature, folk customs, traditions, the importance of the public opinion and the authority of teachers in the rural areas, the majority of parents belong to the same labor collective, their compact residence and constant communication with colleagues outside of work, professional loneliness of teachers, etc. It is important that the problem of the weak accessibility to quality variable educational programs is being addressed. Thus, it is suggested to erase the boundaries between rural and urban general education organizations and the content and technologies of their activities. Accordingly, there is a question of the specificity of the modern rural schools in the information society, which leads to the need for historical and pedagogical analysis of this issue.

From our point of view, numerous peculiarities of rural school have been justified since the middle of the XIX century. Nowadays the peculiarities of the rural Russian schools are unfortunately axiom for specialists. In recent years the methods of their detection, list and content in the historical and pedagogical plan have not been the subject of a separate study. Thus, the relevance of the study is due to the need for systematization on the basis of historical and pedagogical analysis of the theoretical ideas about rural school and its peculiarities. Accordingly, the purpose of the study is to identify on the basis of historical and pedagogical analysis and to systematize the peculiarities of rural school as one of the leading factors of modernization of education of Russia.

\section{METHODOLOGY}

The methodological basis of the study are the main provisions of the network approach, the implementation of which allows to identify and justify the network elements of the organization of the educational process in the rural school, leading ideas of system-activity approach, the use of which provides an opportunity to identify peculiarities of modern rural school. Methods of research are general theoretic (analysis of philosophical, psychological, pedagogical literature on the problem, analysis, generalization, classification, comparison, systematization).

\section{RESULTS}

It can be stated that in pedagogical science sufficient attention is paid to the research of the problems of the rural school. Consider the major findings that form the core of the rural school 's leading development concepts. 1. Among the established scientific definitions it is necessary to include first of all the concept of the rural school (M. P. Guryanova, 2001), which on the basis of historical and pedagogical analysis summarized the available definitions of this group of schools (from K. D. Ushinsky, L. N. Tolstoy to the works of A. Z. Andreiko, M. Zaykin, G. F. Sugor.). Basic (classical) definition is the following: the rural school is represented by a set of different types of organizations located in the rural areas, diverse in the number of students, location, aimed at performing sociocultural and socio-pedagogical functions, labor training of schoolchildren.

The formation of the information society contributed to the socio-cultural modernization of education, within the framework of which the content of this phenomenon gradually began to be revised (L. V. Vohminova, A. M. Ishchenko, L. M. Kobrin, E. P. Kosinov, N. A. Krivolapova, etc.). The thesis "modern secondary rural school is changing" is becoming quite common. Research on this issue peaked in 2008-2015. A number of works (L. V. Bayborodova, L. V. Vohminova, L. M. Kobrin, E. P. Kosinov, I. B. Medvedev, etc.) reveal modern trends in its development. However, until now there is no generally accepted definition of a modern rural school in the scientific literature. There is also no a complete historiographic analysis of the process of development of the modern rural school.

2. The features of the rural school are also fairly invariant. The view of M. P. Guryanova (typical diversity, nonalternative in the educational space, small number, integrativeness, multifunctional activity of the rural teacher, social control, focus on labor education, specifics of the organization of the educational process, etc.) is generally accepted [4]. Among the specialists are used peculiarities of the organization of the educational process (L. V. Bayborodova, N. A. Krivolapova, etc.), based on the works of M. I. Zaykin, G. F. Sugorova, M. P. Bristinan, etc.. In the context of informatization these features are often leveled, which makes us think about their existence in principle. In this regard, the works of L.V. Bayborodova [5], Z. B. Eflova [6] on the specifics of different types of rural schools are especially important. 3. Modern pedagogy presents studies on the problem of classifying rural schools, highlighting their types and species. A special place is occupied by the works of A. M. Tsirulnikov, who was one of the first to justify the types of pedagogical associations as pro-images of the future 
network schools and described the technologies of their formation. However, the most common classification is the M. P. Guryanova (2001) one, which systematized this concept according to multiple criteria. Nowadays there are no common approaches to the classification of the modern school. Thus, a different approach is proposed by M. A. Pinskaya, I. E. Havenson, S .G. Kosaretsky, R. S. Zvyagintsev, etc., highlighting such type of the rural school as resilient. It should be noted that up to now the known types and types of the rural schools are represented in different ways in the regional legislation of the constituent entities of the Russian Federation (L.V. Bayborodova, I. B. Meddvedev, L.V. Nezazova).

4. The issue of models of the rural schools (N. E. Kasatkin, R. M. Sheraizina, etc.) attracts great attention of specialists. Since the 1970s, the modern model of the rural school has been associated with the various models of educational or socio-pedagogical complexes (A. Z. Andreiko, M. P. Guryanova, Z. B. Eflov, A. M. Tsirulnikov, etc.).

5. The conceptual ideas for the development of the rural schools is of considerable interest (A. Z. Andreiko, L. V. Bayborodova, L. V. Vokhminova, M. P. Guryanova, V. S. Gusenko, T. A. Kreslavskaya, O. E. Lebedev, T. V. Orlova, P. P. Pivnenko, G. A. Schetinin). This problem also studied by foreign authors [7-9]. The modern rural school is one of the leading mechanisms of socio-cultural modernization of the education system of the Russian Federation and has a significant influence on the modernization of the Russian education system (content, technologies of implementation). It leads to the need to identify the basic characteristics of this group of general education organizations, the need to create and test mechanisms to identify the specifics of rural schools (conceptual model of modern rural educational institution), the need for practical justification of the peculiarities of rural schools within the framework of the development of the information society.

The conceptual model of the modern rural school takes into account all the peculiarities of the modern information society and is implemented taking into account all local peculiarities (including such elements as organizational structure, resources, ideas and leading directions of activity, mechanisms of organization of the educational process, its subjects, etc.). It is the conceptual model of the rural school that helps to identify research and implement the educational and educational process, taking into account the peculiarities of specific rural subcultures, subjects of the educational process, the foundations of their activities, the mechanisms of organization of the educational process and resource provision. The development of the conceptual model of the rural school of the Russian Federation includes the whole set of interrelated components: educational, didactic, managing subsystems, leading conceptual ideas of functioning and development, mechanisms of organization of the educational process, its subjects, organizational structure, technologies of resource support, etc. The feasibility of developing and implementing the conceptual model of the modern rural school makes it possible to identify qualitatively new directions and principles of organization of its life activity, to systematize them and to find more profitable forms, methods and technologies of their implementation.

The conceptual model develops the concepts of management of the network interaction of the rural schools aimed at ensuring the spectrum of continuous communications of various organizations within the framework of the public-state system of education management. Moreover, the conceptual model makes it possible to develop mechanisms for organizing the educational process at modern rural schools, the application of which provides rural schoolchildren with quality education and personal development in conditions of informatization of education, systematization of scientific and pedagogical ideas about modern rural schools. Such a set of integral components makes it possible to effectively form modern professional representations of teachers, management and pedagogical teams as public-state bodies of network communications management, design and implementation of network educational programs of educational institutions.

Thus the conceptual model of the modern rural school is the leading mechanism of socio-cultural modernization of the village and allows to identify qualitatively new directions and principles of organization of the educational process. The purpose of any conceptual model is always to identify and substantiate the features of modern rural school as one of the leading factors of sociocultural modernization of education. It can be assumed that in general most rural schools primarily solve the problems of social adaptation of schoolchildren as well as M.P. Guryanova 's ideas about the education of a viable person.

6 . The largest number of works devoted to the rural school is connected with the development of its didactic system (according to A. M. Ishchenko - up to 40-60\%). The works can be divided into groups: a) aimed at modernization of the classroom system (unconditional leader of the scientific school L.V. Bayborodova); b) justifying non-compulsory (including different age) system of organization of the educational process (Krasnoyarsk scientific school of collective method of education, in particular M. A. Mkrtchyan, V. B. Lebedintsev, etc.).

7. In separate studies of 2015-2020 separate patterns of development of the modern rural school in Russia were established and proved (formation of rural school as an open network general education organization; the focus of the content of the educational process on the design and implementation of variable educational services, which ensure the formation of social and personal success of graduates; feasibility of modeling of the rural schools taking into account national-regional specificities, etc.) $[10,11]$. 
8. A large number of studies are related to the preparation of teachers for work at the rural school (F. F. Avdeev, L.V. Bayborodova, N. G. Neztroev, R. M. Sherayzina, etc.). From the point of view of L. V. Bayborodova the analysis of scientific publications showed that the pedagogical aspects of the process under study have not been studied much [11].

\section{CONCLUSION}

It can be stated that certain features of the rural school have been justified since the middle of the XIX century (K. D. Ushinsky, P. M. Kapterev, S. A. Rachinsky, etc.) and often only on the basis of subjective individual empirical studies.

Later the numerous studies have already been carried out taking into account these works and the same methods. Exceptions include a number of comprehensive programs to study rural schools, including L.V. Bayborodova, V.G. Bocharova, M. P. Guryanova, G. Sugorova, etc. The methodology of research of the rural society and the rural schools by G. Sillaste is also fundamental. The relevance of this issue is obvious and confirmed by the studies carried out in 2015-2019, which affect the personality of rural teachers [12], assessing the effectiveness of his professional activity [13]. Comprehensive research of the individual rural schools of the Saratov region [13], the Republic of Chuvashia [14] became interesting. But the very peculiarities of the Russian rural schools are still axiom for specialists almost regardless of the stages of the development of society.

The research programs presented in the publications, which justify the specific features of rural schools, will make it possible to develop a comprehensive program of the research of the modern rural schools, which helps to identify and describe, taking into account the specific rural subcultures of the subjects of the educational process, the leading organizational models of the rural schools, the conceptual foundations of their activities, the mechanisms of design and organization of the educational process, work with the society and resource provision.

Accordingly, such study will contribute to the development of the conceptual model of the modern school as the leading mechanism of socio-cultural modernization of the village, including a set of interrelated components: educational, didactic, management subsystems, leading conceptual ideas of functioning and development, mechanisms of organization of the educational process, its subjects, organizational structure, resource support technologies, etc.

\section{ACKNOWLEDGMENT}

The reported study was funded by RFBR, project № 19-313-90052.

\section{REFERENCES}

[1] M.V. Belov, D.A. Novikov, Network active systems: models of planning and stimulation, Problems of management 1 (2018) 47-57.

[2] L.M. Gohberg, G.G. Kovaleva, N.V. Kovaleva, Education in numbers: 2018: short statistical collection, Higher School of Economics, 2018, pp. 26-34.

[3] A.M. Tsirulnikov, Sociocultural Project as a mechanism for the development of education in the region, Pedagogy 11 (2019) 25-33.

[4] M.P. Guryanova, Rural Society of Modern Russia as a space of resources and risks of socialization of children, in: Scientific research of problems of childhood, upbringing, socialization: topical aspects, theoretical and methodological bases Collection of scientific works, 2018, vol. 1, pp. 176-184.

[5] L.V. Bayborodova, Modern economic and social conditions of education of rural schoolchildren, Pedagogy of rural schools 1 (2019) 9-23.

[6] Z.B. Eflova, On the Relevance of the Definition of Small School, Continuing Education: the 21st Century 1(17) (2017) 100-107.

[7] P. Sahlberg, Teaching and globalization, International Research Journal of Managing Global Transitions 2(1) (2004) 65-83.

[8] J. Coolahan, Teacher Education and the Teaching Career in an Era of Lifelong Learning, in: Directorate of Education, 2002, pp. 7-12.

[9] A. Pendola, E.J. Fuller, Principal stability and the rural divide, Journal of Research in Rural Education 34(1) (2018) 1-20.

[10] I.B. Medvedev, Network organization of educational process in modern rural school: autoreferate diss. of Candidate of Pedagogical Sciences, Veliky Novgorod, 2018, 24 p.

[11] Y.P. Yeretnova, E.E. Sartakova, Peculiarities and stages of formaton of the modern rural school, Pedagogical Review 5(27) (2019) 83-89.

[12] M.A. Amirov, V.N. Antoshkin, Social Portrait of a Rural Teacher: Results of Comparative Study of Rural and Urban Teachers, Modern Research of Social Problems 9 (2017) 5-24. 
[13] K.M. Zainetdinova, N.L. Zarubina, S.A. Karasev, On the state and prospects of development of rural schools in the Saratov region, Journal of the Saratov Regional Institute of Education Development 2 (2019) $121-126$

[14] A.E. Ilin, E.V. Ilin, Chuvash rural small school as an educational system: a mognograf, Cheboksary, 2018, 234 p. 